Radial and Nonradial Pulsations as Probes of Stellar Physics

ASP Conference Series, Vol. 259, 2002

C. Aerts, T.R. Bedding, $\mathscr{G}$ J. Christensen-Dalsgaard, eds.

\title{
Reminiscences on Two Papers by Paul Ledoux
}

\author{
D. O. Gough
}

Institute of Astronomy, Madingley Road, Cambridge, CB3 OHA, UK, Department of Applied Mathematics and Theoretical Physics, Silver Street, Cambridge, CB3 $9 E W, U K$ and

Physics Department, Stanford University, Via Palou, CA, 94305, USA

Two of the papers by Paul Ledoux that were discussed in the tribute by Paul Smeyers are worthy of further comment, by virtue of the circumstances under which they were produced. I heard the stories originally from Chandrasekhar, and subsequently had their essence confirmed by Paul, and in the second case also by Chiam Pekeris. I have checked with Ed Spiegel that I have remembered the stories correctly.

The first paper on which I comment is the one published in 1945 in the Astrophysical Journal. Paul had been in Norway, working with Rosseland, when Belgium was invaded in the second world war. He escaped to Yerkes Observatory, but felt that he should really be with the free Belgians. He volunteered for military service, and went to the Belgian Congo as a meteorologist. As was the case with many scientists at that time, his formal duties did not occupy him fully, and in his spare moments he was able to think about astrophysics. He developed the use of the virial theorem for the estimation of the periods of pulsation of nonrotating and rotating stars.

In the time he had been at Yerkes, Paul had developed a friendship with Chandrasekhar, and he knew that Chandra would be interested in his work. Paul therefore wrote to Chandra explaining it, and Chandra was indeed interested. In fact, so interested was Chandra that he wanted to develop the use of the virial theorem further, but he could hardly do so until Paul's work was published. But Paul was in the jungle far away, hardly in a position to prepare a paper; and in any case the mail was slow and uncertain. So Chandra adopted a pragmatic approach: he wrote the paper himself under Paul's name, recorded his indebtedness to himself for his help in recasting the original paper in a more presentable form ..., and submitted it for publication in the journal of which he had recently become Associate Managing Editor. He refereed the paper himself, as he did many of the papers that were submitted to the Astrophysical Journal during his editorial days - and those he didn't referee he certainly read with considerable care; he accepted it, and sent a copy to Paul. By the time Paul first saw it, the paper had already been published.

My second comment is briefer: it concerns the earlier paper published in 1941 with Chiam Pekeris, also in the Astrophysical Journal, on estimating the frequencies of radially pulsating stars under a variety of circumstances using a variational principle. What happened on this occasion is that Chandra received at the same time two independent papers on the same subject to referee, each coming to the same conclusions, one from Ledoux and one from Pekeris. So 
Chandra returned them, suggesting that the two collaborated to write a single paper. This they did, by correspondence. Yet despite their common interest, the two men never ever met.

Paul was a man of high moral integrity; he also had impeccable taste, particularly in food and wine. Moreover, he was a man of great stamina, not excepting his performances at the dinner table. Ed Spiegel tells of a time at Princeton, in the days of the work with Martin Schwarzschild on the spectrum of turbulent convection, when Paul was feeling tired and Ed had persuaded Paul to join him at a French restaurant to relax; they had a good meal and some fine wine. On their way home, around 9:30 pm, they encountered an exasperated Mogens Rudkjøbing waiting in the square: Mogens had invited Paul to dinner that evening and had arranged to meet him in the square at eight, in order to show Paul the way to his house. Paul had completely forgotten, but he feigned an unavoidable delay involving Ed, with profuse apologies. Naturally, Mogens invited Ed to dinner too, and, seeing that Paul needed moral support, Ed accepted to come for the company, but he excused himself from eating on the ground that he had just had dinner. They arrived at the house, the only guests, to det store kolde bord (i.e. an enormous smörgåsbord); Paul was a stalwart gentleman, and heartily ate a second enormous meal.

\section{References}

Ledoux, P. 1945, ApJ, 102, 143

Ledoux, P. \& Pekeris, C.L. 1941, ApJ, 94, 124

Ledoux, P., Schwarzschild, M., \& Spiegel, E.A. 1961, ApJ, 133, 184 